\title{
El amorfino como género lírico de tradición oral: principio e institución de la copla de amor montubia*
}

Fecha de recepción: 30 de noviembre de 2021

Fecha de aprobación: 27 de diciembre de 2021

\section{Resumen}

Este artículo reflexiona sobre la copla de amor montubia, conocida en el litoral ecuatoriano como amorfino. El estudio repasa cualidades del amorfino como género lírico de tradición oral e introduce sus rasgos formales y temáticos. Se señalan algunas distinciones y similitudes de esta poesía popular dentro de la lírica de tipo tradicional. En cuanto a su conceptualización y cercanía a otras formas poéticas, se observan semejanzas notables con la poesía popular de tipo tradicional y con otras formas del folclor hispano. No obstante, se descubren rasgos particulares en su expresión antropológica, producto del contexto en el que se arraiga y de sus usos y su finalidad. Su manifestación dentro del velorio montubio sitúa esta tradición oral como una importante expresión lúdica de aquellos campesinos. Los juegos de rueda mediante la declamación del canto sirvieron para la vida erótica y la vida social, y cohesionaron la convivencia de esas gentes.

Palabras clave: amorfino, copla de amor, lírica tradicional, poesía popular ecuatoriana, tradición oral.

Citar: Pérez Martínez, Javier. "El amorfino como género lírico de tradición oral: principio e institución de la copla de amor montubia”. La Palabra, núm. 41, 2021, e13775 연 https://doi.org/10.19053/01218530.n42.2021.13775

\section{Javier Pérez Martínez}

Doctor en Estudios Artísticos, Literarios y de la Cultura por la Universidad Autónoma de Madrid. Ha sido docente en varias universidades de Ecuador.

jperezmtnez@hotmail.com

(1Dhttps://orcid.org/0000-0002$\underline{0375-4807}$

* Artículo de reflexión derivado de la tesis doctoral titulada: Poética, Retórica y memoria en el Amorfino: coplas de amor montubias. 


\title{
Amorfino as a Lyrical Genre of Oral Tradition
}

\begin{abstract}
This paper studies "copla de amor montubia" [Montubia love couplet] -better known in the Ecuadorian coast as "amorfino". The research, regarding this type of oral lyric poetry, emphasizes in its formal and thematic characteristics. Therefore, it is shown some differences and similarities between popular poetry and lyric poetry. From the theorization of these two ways of poetry, it is showed the similarity of popular poetry and Hispanic folklore. Additionally, it is highlighted the anthropological point of view due to its social contexts. This form of poetry is stablished in the "montubio" mourning, which is a traditional and ludic way of life of the Ecuadorian peasants from the coasts. In this tradition, there are "juegos de rueda" [traditional rounds] which have worked as a form of erotism, social life, and as way to stablished social attachment.
\end{abstract}

Key words: Amorfino, love's couplets, traditional liryc, Ecuadorian popular poetry, oral tradition. 


\section{O amorfino como gênero lírico da tradição oral: princípio e instituição da copla de amor montubia}

\section{Resumo}

Este artigo reflete sobre a copla de amor montubia, conhecida no litoral equatoriano como amorfino. O estudo analisa as qualidades do amorfino como gênero lírico de tradição oral e introduz seus traços formais e temáticos. São assinaladas algumas distinções e semelhanças dessa poesia popular dentro da lírica de tipo tradicional. No seu conceito e proximidades se identificam semelhanças notáveis com a poesia popular de tipo tradicional e com outras formas de folclore hispano. Contudo, são descobertos traços particulares na sua expressão antropológica, produto de contexto no qual está fixado e dos seus usos e finalidades. A sua manifestação no velório montubio situa essa tradição oral como uma importante expressão lúdica dos camponeses. As cirandas mediadas pela declamação do canto serviram para a vida erótica e a vida social, e ligou a convivência dessas pessoas.

Palavras-chave: amorfino, copla de amor, lírica tradicional, poesia popular equatoriana, tradição oral. 


\section{Fundación del género y concepto de copla}

En las costas y montes del litoral ecuatoriano, tras la conquista de América por la corona de Castilla, se concibe una poesía popular en lengua castellana. La transmisión oral de cantares, romances, décimas y coplas germina en la región — de lo que hoy se conoce como Ecuadora orillas del Pacífico. Con el mestizaje y la criollización lingüística se instituye un acervo cultural hispano cuya forma lírica deriva en lo que se conoce como amorfino. Esta poesía popular, muy cercana a la poesía de tradición oral castellana, presenta algunas particularidades semánticas fruto del contexto y una genuina forma de expresión en los velorios de navideños, allí conocimos como chigualos. Estas coplas de amor se transmitieron de generación en generación y conformaron un sentido de pertenencia e identidad entre hombres y mujeres del campo. Con el paso del tiempo, se establecen juegos de rueda (o rondas) en las aldeas donde se arraigan esas expresiones líricas y toman gran importancia para la convivencia y la vida erótica. Entrado el siglo XX, el amorfino pierde paulatinamente funcionalidad y gana presencia en teatralizaciones de centros urbanos más poblados.

La llegada de los colonos a América en el siglo xiv propició la expansión del español y su cultura en las colonias del "nuevo" continente. La emisión y dominio de los hispanohablantes se establece con los criollos. Los descendientes de españoles nacidos en América encarnan la consumación de la denominada "criollización lingüística", según Frago Gracia, en su libro Historia del español de América, nombre con el que se conoce proceso inicial para la conformación dialectal del castellano en América (Marimón Llorca, "El español en América: de la conquista a la Época Colonial"). En la difusión social del idioma, aunque con matices, predominó el carácter vinculado al origen de los conquistadores, es decir, mayor proporción de voces del sur peninsular: "en su meridionalismo fonético se fraguó la primera gran nivelación del español en Indias, con la señalada impronta de seseo y del ceceo de andaluces y canarios" (Frago Gracia y Franco Figueroa 23). En virtud de esa primera nivelación del español en América también se fundará el folclor regional, consecuencia a su vez de la tradición oral iberorrománica.

Los conquistadores y después colonos introdujeron la canción de la época que durante el Siglo de Oro fue asumiendo modificaciones. El diálogo entre la poesía culta y la poesía popular fundió las formas y temas en una nueva lírica popular. Los grandes poetas del Renacimiento nutrieron sus creaciones artísticas del romancero viejo y cancionero popular, además favorecieron la sustitución de villancicos por la canción nueva, la laica y la semiliteraria. Esa herencia de cancionero semiliterario, según Kofman (65), constituyó "la capa primaria de la poesía popular hispanoamericana, a partir de la cual se formaron otros géneros del folclor criollo".

Al establecerse los géneros españoles en el Nuevo Mundo, se acomodaron los más convenientes a la transmisión oral. Se prestó para ello: la disolución étnica (Sánchez-Albornoz), la asimilación del castellano como lengua común de los pobladores y una sociedad de base ágrafa. Todo lo anterior, favoreció a la trasmisión de un cancionero perpetuado por siglos. Es pertinente hablar de poesía tradicional cuando es evidente que se trata de una lírica participativa que durante cientos de años se nutre del acto de habla popular. A través de ella se 
expresan o han expresado los pueblos y la han dado de herencia. Entre sus cualidades está ser apta para ser deformada o reformada, "conformándose al gusto común de cada tiempo; estas variantes ejercen una función creadora o re-creadora; así la poesía arraigada en la tradición vive en variantes y en refundiciones" (Menéndez Pidal Poesía árabe y poesía europea).

En su origen, del latín, la palabra copla procede de copula (unión, atadura), construido con el prefijo co (conjuntamente) y, del latín, ap (coger, alcanzar) también raíz del verbo latino apere (atar, ligar) (Pastor de Arozena y Roberts). Otra asociación etimológica más tardía, del siglo xvi, respalda que el legado de la palabra copla viene del vocablo latino copula. Copla refiere tanto a la composición poética en el que se unen versos o estrofas livianas, como a la finalidad discursiva de esta canción popular, cuya motivación consiste en persuadir o despertar el amor, mostrando los deseos o inclinando las preferencias eróticas, hacia una o un escuchante, con el propósito de merecer su interés o "cópula". En todo caso, la aspiración es unir, ya sea amorosa, erótica, sexual o sintácticamente. Por lo tanto, no es raro pensar que, entre españoles, el éxito de la copla responda a estas dos ideas, cimentadas en la Retórica (Albaladejo 12); tanto la sencillez métrica, como la capacidad para influir en el receptor. La llaneza técnica para recitarse permitía distinguirse, y más entre capas populares, siendo una forma de contar con las armas suficientes para convencer en el amor o ganarse la adulación de los otros. No parece que se extienda el uso social de la copla castellana sin ambas nociones.

Encuentra Tomás Navarro Tomás su origen y asiento: "La copla de arte menor y la castellana procedían de la misma fuente provenzal [...] La realidad es que la copla castellana venía a reavivar la latente tradición de la redondilla" (130). Tanta vitalidad tuvo entre las gentes que acompañó a los conquistadores en todas sus singladuras a las Indias y allí la sembraron para la posteridad, como lo observa Justino Cornejo en la "Poesía popular ecuatoriana":

Viajera en las naves de la Conquista, la copla llegó a esta inmensa porción del Mundo desde el siglo XV. Y aquí la escuchamos, la hemos escuchado y seguiremos escuchándola, lo mismo en ciertas regiones de los Estados Unidos que antes fueron territorio mexicano - territorio hispanoamericano-, que en las riberas de Cuba; lo mismo bajo el sol ardiente de los llanos, que entre los riscos gélidos de los Andes; lo mismo en las selvas que en los valles. Ella, la copla, vive aquí, retoña con cada aurora, como el refrán, como la conseja, como la adivinanza, como el mito; como todas aquellas manifestaciones del alma española que hermanan fuertemente a estos pueblos de América y que nos acerca, querámoslo o no, a España, a nuestra España (5).

Y ese brío y fertilidad de la copla en América es visto también por otros autores así:

La copla popular española agarra mucha vida legítima. Desnuda como una piedra se anda por los caminos del idioma. Se cantó y se canta aún por toda España, como su primera y precisa habla. La trajeron a la América los colonizadores y aquí creció y se transformó, en los pueblos creciendo, y se anduvo en la América en tabernas y buchinches, vendutas y teatrillos, como forma de canciones ya distintas, en trovadas de vario acento, cada vez más independiente (Feijó 17).

La copla en Ecuador creció y se transformó en amorfino, que no tuvo lugar cubierto, tampoco gradas para el aplauso, ni ventanas por donde se escapara el coro que privara acompañar el canto. Encontró cobijo bajo un techo de cade y una casa de caña, pues los diluvios del invier- 
no intimidan con aguar el velorio. La copla se extendió entre las gentes que la escuchaban muy viva en las casas. Su declamación espontánea preparaba el encuentro más lúdico y formal. Así la nieta aprendía de su abuela versada en los juegos de chigualos o de aquella tía con tanta desenvoltura para el verso, y que a fuerza de repetir la tradición terminará por enseñar y transmitir a una de sus descendientes.

Aquellos pobladores bebieron de sus predecesores la nueva forma de canción durante los siglos de la conquista, colonia y encomienda de indios (xvi, xvii y xviii). La copla popular se divulgó bastante por su rima entre el verso segundo y cuarto, dejando los impares libres. Esto ocurrirá igualmente en el amorfino, en la que será muy habitual escucharse entre campesinos canciones amatorias y en contrapuntos. Esas coplas con métrica simplificada se reducen en su mayoría a la sola rima en los versos pares, a menudo, consonantados (sino gramatical prosódicamente) mediante agudas. Tan abundante es esta cuarteta que suele ser la recordada cuando es recitada. Con frecuencia, rima el mismo diminutivo, el gerundio, el infinitivo o repite su conjugación. En el canto mantiene el atractivo, sin embargo, siendo recitada, la rima consonante de palabras llanas se escucha trivial en algunos casos como los que siguen. ${ }^{1}$

Tres veces partí sandía tres veces partí melón tres veces partí mi alma por darte mi corazón.

Allá arriba en ese cerro tengo un pañuelo volando en las cuatro esquinas dice ya mi amor se está acabando.

Una estrella se ha perdido y en el cielo no aparece en tu casa se ha metido y en tus labios resplandece. ${ }^{2}$

El cielo se está nublando como que quiere llover así se ponen mis ojos cuando te dejan de ver. ${ }^{3}$

\section{Rasgos y parentesco del amorfino como (sub)género de tradición oral}

\footnotetext{
Varias de las estrofas aquí citadas están recogidas directamente de los cuadernos que las informantes conservaron para refrescar la memoria cuando se acercaran las fiestas y, por tanto, el canto de versos.

Cuaderno Inés Rivera, Canuto.

Cuaderno Elicio Alcívar, Canuto.
} 
La lírica tradicional, donde se ajusta el amorfino, se ciñe a su soporte de comunicación: la oralidad. Siguiendo a Walter Ong (41), la cultura oral ostenta esas psicodinámicas de dinamicidad y ritmo pues se limita a lo que uno puede recordar, y ello depende de "las pautas equilibradas e intensamente rítmicas". Además, como pensamiento oral, se fundamenta en que: es acumulativo antes que subordinado y analítico, es decir, se vale de menor sintaxis y hace un uso frecuente de epítetos; es redundante, lo cual estimula la fluidez; que es conservador y tradicionalista, pues reprime la experimentación intelectual; es humanamente vital por inmediato; es agonístico, ya que se presenta en combate verbal y retórico con intercambio dialéctico; es empático por la respuesta instantánea de lo que pasa; dado que tiende al equilibrio, se puede decir que es homeostático; y, finalmente, es situacional antes que abstracto, puesto que no clasifica ni formula silogías.

Contando con los anteriores fundamentos, el amorfino se expresa en el diálogo o contrapunto, es decir, en la réplica e intercambio entre quienes formulan sus versos. Curiosamente, el equilibrio se contendría en "ese diálogo" posible en la vida de la tradición y situación de sus portadores. Continuando con las tesis de Walter Ong, las psicodinámicas de la oralidad determinan las formas de versos simples dotados de gran desenvoltura y su condición lacónica, rasgo común de las culturas orales, donde se condensa el fondo y se repiten versos, ideas, figuras retóricas o tropos; todos signos idóneos para facilitar su memorización y transmisión.

La evolución de los géneros se reconoce en múltiples factores, tanto socio culturales, por la distinta realidad de aquellos descendientes hispanohablantes no nacidos en España, como formales, por la cómoda sintaxis que se ajusta a la literatura de tradición oral. El amorfino, como canción lírica (Gómez López y Pedrosa Bartolomé 20), expresa de forma concisa emociones y sentimientos, y se destaca por ser breve. Por su estilo, se inserta en géneros de literatura tradicional que se diferencian con la literatura escrita por: a) la brevedad; b) las fórmulas orales recurrentes (por ejemplo, muchos versos de apertura — embonó- como: "En el centro de la mar...", “Ayer pasé por tu casa...", “Allá arriba en esa loma...”); c) el ritmo o prosodia (entonación o modulación de la voz); y d) la comunicación extratextual o gestual para la recepción. Antonio Sánchez Romeralo (174) señala que la canción breve es "la forma natural de la lírica castellana" (y valga decir en castellano). Por ende, la brevedad "es su carácter esencial" de estilo, por esto este autor se observa que fue primero en el villancico y después en la seguidilla o la copla ("que son los villancicos de hoy") que se dio esta característica.

Sobre el cancionero propagado en América, se antepuso el uso de la estrofa de cuatro versos octosilábicos. Cuartetas que unas detrás de otras se conocerán como coplas, vocablo que servirá al estudio por contener una vasta significación, que abrazó dos ideas elementales relacionadas (Moliner): 1) por tratarse de una composición estrófica breve y de métrica sencilla - "generalmente de cuatro versos"- que pone letra a canciones populares; y 2) por ser canto o género de canto popular. Una cuarteta detrás de otra, juntas o por separado, comprende la idea de copla y supone una amplia denominación que mencionan en los diccionarios. En su acepción dice, sirve en la lírica popular para reunir conjuntos de estrofas: "cualquier estrofa de tamaño regular que no exceda de ocho versos es catalogada bajo esta denominación" (Canino Salgado 32). 
Con el trasegar del tiempo proliferaron los versos de arte menor y la estrofa independiente de cuatro versos rimados en los pares. Menos populares serán las redondillas (abba) rimando el primer verso con el cuarto y el segundo con el tercero; o las cuartetas de rima perfecta (abab). Estas composiciones de cuartetas octosilábicas se familiarizan por su estilo con los villancicos, el mote, la canción y el breve poema con cabeza vuelto, designado de nuevo como copla en los cancioneros. Su estructura interna casa con el romance tradicional de doble octosílabo o verso de dieciséis sílabas (Sánchez Romeralo 147). Con dichas estructuras arraigó el verso octosílabo por ser el más apropiado y natural en lengua castellana (García Berrio y Huerta Calvo 162) y se consolida por su ligereza para ser cantada como la poesía entre indianos (españoles, criollos, mestizos...) y, aún, nativos.

Las fiestas de los llegados a América serán amenizadas por la circulación escénica de los grandes dramaturgos de la época y la pujanza de sus formas poéticas. Serán las variaciones de la dramaturgia de la época y de un teatro misionero pormenorizado lo que parece el primer germen del velorio del Niño y el amorfino. Los Autos y Coloquios del xvi se registraron en varias ciudades de la época (Teodosio Fernández, Millares y Becerra 52) y pudieron haber evolucionado a lo largo del periodo colonial. Un teatro barroco trasformado en breves escenificaciones o rancho de ánimas, como ha señalado Trapero (486), es un género poético que el mismo autor ha estudiado en Canarias y este vive en la oralidad, su repertorio memorizado resulta habitualmente improvisado.

En la península Ibérica se encuentra el vínculo popular con diversas líricas que tiene como característica el hermanamiento en los temas y dramatización. Por el siglo xv, el Marqués de Santillana reunirá estribillos populares castellanos y, más tarde, durante el periodo de los Reyes Católicos, los colectará Juan del Encina, sumando el Cancionero de Palacio. Rafael Lapesa (144) valora el interés por el género de entonces, todo ello "señala el gusto renacentista por la canción tradicional que, sin decaer en el siglo xvi, culmina hacia el 1600, sobre todo con Lope de Vega y Góngora". Ramón Menéndez Pidal observa que, en tiempos del imperio, cesa la influencia arábico-románica medieval cuando confluyeron en la península el sistema árabe por Andalucía y el occidental-provenzal por Galicia. Esas nuevas evocaciones y cantares se extienden a ultramar.

En nuestro teatro clásico, tan rico en cantos líricos populares y tradicionales, se recogen las últimas muestras de estrofas zejelescas, siempre entonadas en pobres fiestas de labradores. Así se extinguen en su patria los últimos ecos de la canción arábigo-andaluza la que en los siglos xi y xii tuvo tan gloriosos destinos en Oriente y Occidente. Se extingue su voz en el siglo xvii, ahogada por la incipiente boga de otra nueva forma de canción, la copla y la seguidilla, también nacidas en la eterna Andalucía. A las fiestas fluviales sobre el Guadalquivir, y sabia corte de Motámid o en los días de Aben Guzmán, cantadas en estrofas zejelescas, suceden las fiestas de la época de Felipe IV y de Lope de Vega, cantadas en las nuevas coplas, cuya boga aún dura (Mendéndez Pidal, Poesía juglaresca y juglares 78):

¡Ay, río de Sevilla, -cuán bien pareces

lleno de velas blancas- $\mathrm{y}$ ramos verdes! 
La referencia al río se destaca habitualmente en la lírica tradicional, es constituyente de los paisajes con lo telúrico y astral, junto a otras referencias de la naturaleza. También aparece entonada con frecuencia en la canción montubia: en canciones amatorias, de confesión de desamores, resignación o lamentos por la ausencia de amor. Tema que se conecta con todo el tronco de poesía amorosa de tipo tradicional en occidente, de origen provenzal, por ejemplo: las cantigas de amigo y cantigas de amor.

Beneficiada en su composición por esa canción primera de Andalucía, dicha poesía amorosa se cultivará en la lírica castellana (Deyermond). Un ejemplo es la siguiente alborada, comparada con la tradición hispanoamericana. Al margen de los paralelismos, se perciben similitudes de fondo con el amorfino, las primeras por la viveza del río, situación donde la naturaleza alcanza una gran trascendencia simbólica por un cierto transcurrir emocional (Pérez Martínez); las siguientes en alusión al deseo de venida y presencia del amado(a), nada lejos en la avidez de quien canta.

Me senté a la orilla del río

a la sombra de un laurel

de ver las aguas correr

me acuerdo de usted bien mío. ${ }^{4}$

A orilla del río grande

suspiraba un picaflor

y en el suspiro decía

en dónde estará mi amor. ${ }^{5}$

Qué lejos está mi amor

que yo no lo veo aquí

si lo tuviera a mi lado

fuera gloria para mí. ${ }^{6}$

A mi amigo yo le quiero

y le tengo estimación

y lo cargo retratado

dentro de mi corazón. ${ }^{7}$

$\mathrm{Al}$ alba venid, buen amigo, $9 a^{8}$

al alba venid $5+1=6 \mathrm{~b}$

Ordóñez Iturralde (98).

Rivas (156).

Cuaderno Vicenta Bazurto, La Chorrera, Canuto.

Cuaderno Inés Rivera, Canuto.

Deyermond (60). 
Amigo el que yo más quería, $8 \mathrm{c}$

venid al alba del día $8 c$

Amigo el que yo más amaba, $9 d$

venid a la luz del alba. $8+1=9 d$

Venid a la luz del día, $8 c$

non traigáis compañía $7 c$

Venid a la luz del alba,8d

non traigáis gran compaña7e

Dámaso Alonso ("Introducción") mantiene que aun habiendo indicios no se puede probar la tradicionalidad de muchas de las canciones escritas siglos después por Lope u otros autores del siglo xvii. Sin embargo, "esos cantares de tipo viejo o popular que introducen en sus obras nos han conservado una gran parte de la poesía lírica española de antigua procedencia" (11). De ese modo, será más justo definirlas por el tipo tradición que se inscribe. Pensemos la poesía de tipo tradicional como un torrente de caudal de varios afluentes que, aun no siendo idéntica a la popular, bebe de esta y sirve para los mismos motivos: saciar la sed (sentimental) de los pueblos. Incluso, viejos versos de juglares rectificados por grandes poetas fueron devueltos a la cultura popular, y el pueblo hizo algo propio conformándolos a la tradición. De ahí que sea una poesía de todos, colectiva, como defendería Ramón Menéndez Pidal. Su teoría tradicionalista parece la más justa y acertada, pues la colectividad colabora en su creación siendo compartida por más y menos cultos.

\section{Algunas distinciones de fondo}

$\mathrm{Al}$ respecto, conviene referir hitos y hallazgos que revelan algo de la genética de cada cantar popular. El amorfino es la continuación de una canción amorosa que asienta con el cancionero de la nueva canción implantada por los españoles en América. Quizá por aquel entonces, el pueblo solo producía cantos vulgares (Díaz Viana) y, sin embargo, hasta hoy algunos cantos respiran, a menudo, ese aire primitivo de poetas árabes y hebreos, quienes hacia el año 900 tomaron estas jarchas populares para componer sus más cultas moaxajas (Deyermond 30). La más primitiva lírica en lengua romance y, por tanto, la primera poesía lírica de la que se tiene noticia en Europa (siglo xi) (Alonso y Blecua xxii) enriquecerá el cancionero peninsular, después tan propagado en ultramar.

El encuentro amoroso es tema recurrente de toda poesía; asimismo, lo son las penas de amor, la desazón por la ausencia y la imposibilidad de olvidar al amor. Comparemos una jarcha hispano mozárabe cantada por una mujer, en torno al año 1000, con alguna de las cuartetas que han sido transmitidas por el trópico, hace pocos decenios: 
Vaysemeu corazón de mib,

ya, Rab, ¿si se me tornarád?

¡Tan mal mi doled li-l-habid!

Enfermo yed, ¿cuándo sanarád?

Mi corazón se me va de mí,

oh, Dios, ¿acaso se me tornará?

¿Tan mal me duele por el amado!

¿Enfermo está, ¿cuándo sanará? (Alonso 23).

Dolores y penas mías

con suspiros y lamentos

ay que me muero de amor

y que vivo en gran tormento.

Ya se va de aquí amor mío

por esos lejos caminos

mi alma no queda en calma

mi corazón va contigo.

Alegría cuando viene

tristeza cuando se va

siempre está mi corazón

pensando si volverá.

¡Qué triste que va la luna

cuando no lleva lucero!

Así está mi corazón

el día que no te veo.

Con el pesar de la noche

se oyen ruido de condenas

es mi corazón que sale

buscando olvidar sus penas.

En el amorfino, si bien existen aspectos que destacan el amor cortés, no podría ser nunca catalogada como poesía cortesana. Es más, en virtud de los rasgos (Deyermod 43) que se atribuyen a los poemas de amor puro, multitud de las coplas montubias se vuelven su reverso. Por referir alguno, aquel amor cortesano es trágico y no cómico; y este amor montubio, 
en cambio, en sus representaciones es más cómico que trágico, más cuando atendemos a nuestras conjeturas sobre cómo la tradición se vuelve hacia el contento de una audiencia. Considerándose como el extremo de la sencillez compositiva y situándose en el lado opuesto, respecto a las características de las canciones de los poetas provenzales, su coincidencia es mayor con la juglaresca, más propiamente popular, lo cual no quiere decir inculta; pero sí en un inicio concebida por las clases populares, no conocedoras del latín. "Los juglares conciben la nueva poesía como un espectáculo o diversión pública, y de aquí derivan los rasgos más peculiares de su arte" (Menéndez Pidal, Poesía juglaresca y juglares 42).

Los indicios vinculan al amorfino ${ }^{9}$ de versos chocantes o de sátira ${ }^{10}$ con la humorada del Arcipreste de Hita, quien rompe en la Baja Edad Media con esa tradición purificadora, ascética y trovadoresca del amor cortés, usualmente, sin recompensa y reciprocidad. "Frente al espíritu ascético de antes, surge, en vigorosa rebeldía, el espíritu mundano (porque es humanal cosa pecar)" (Menéndez Pidal, Poesía juglaresca y juglares 145). Diríase que, ya la relación de amor no toma forma de vasallaje donde la amada es señora del amante, vasallo. Tampoco ocurrirá esto en el amorfino, donde el montubio no se siente "inferior a la amada, se dispone a la misma altura que la montubia a la que desea conquistar" (Pérez Martínez 100).

Por su parte, los versos de amor ostentan un fondo por un amor verdadero y honestidad que contrasta con algunos de los de ofensa, que en ocasiones reprochan el amor de la mujer supeditado al interés o la relación mediada por el dinero. Ese segundo sentido se acerca al ideario burgués emergente de aspiraciones de estatus que refleja una sociedad latinoamericana que se va urbanizando a finales del siglo xix (Monroy Zuluaga 80). A ese nivel, el amorfino se presenta lleno de versos de sátira, ofensa y escarnio, una constante en las formas líricas peninsulares. "Las cantigas d'escarnho e de maldezer, Se trata de invectivas procaces elaboradas ingeniosa y cómicamente, y se hallan dirigidas, en su forma típica, ¡contra la víctima a la que se nombra!" (Deyermond 45). En el amorfino, la sátira se estimularía en el duelo verbal entre sexos, por ejemplo, con el primer verso de insistencia y la comparación con animales para la burla, a diferencia de otras estrofas que toman otra fauna o flora que portan un potencial erótico.

Las mujeres de hoy en día

desde chicas son coquetas

aún no tienen quince años

y ya arreglan la maleta.

Los hombres de este tiempo

9 Un breve estudio que realicé — De la trova al Amorfino y del juglar al montubio... - compara concepciones erótico amorosas a partir de otras referencias poéticas: el trovador y el juglar (Pérez Martínez 100).

10 En el libro Versos de amor y sátira en el Amorfino: estudio y clasificación de la copla montubia explico la división de coplas en dos grandes apartados. Los versos de sátira también se señalan como los conocen los paisanos chocantes o coloraos. 
son como el chapulete ${ }^{11}$,

se llevan a las mujeres

y no saben coger (un) machete. ${ }^{12}$

Además, se observa ese carácter lascivo:

Las aguas buscan lo ríos

los ríos buscan el mar

yo solo busco tus labios

para poderte besar. ${ }^{13}$

No por ello desaparece la conciencia de dolor propia y la moral cristiana extendida en el trópico con el catecismo.

Una flor en el camino

hace pecar al más santo

comete mal desatino

y hace dos mil quebrantos. ${ }^{14}$

Popularmente se habla de versos del Niño, versos de amor, versos chocantes... Los primeros se refieren a los villancicos populares con tonadas propias y cantados en contrapunto que intercalan un estribillo con la estrofa que repiten las cantoras al pesebre. Los dos últimos entran en ese gran cajón de amatorios y contenciosos, unos porque reclaman o recuerdan la unión, otros porque la rechazan. Las gentes de la región llaman versos de amor incluso a los que no tiene por objeto el enamoramiento o reflexionan sobre el amor en abstracto. Suelen ser refranes, consejos o dichos. A veces los llamarán versos sencillos, pues en su labor pedagógica aparentemente nadie se sentiría aludido. Con frecuencia el amorfino abarca varias temáticas. $\mathrm{Su}$ giro resulta un hispanismo, amor-fino de la fina'amor del provenzal. Como amorfino se conforma como algo de sentido propio. Precisamente en la costa del Ecuador se instituye por su fundamento, pues se va afianzando para dar razón a su existencia y costumbre. Tal es el punto que se ha concebido como un ejercicio de arte poética practicada e imaginada colectivamente. Cornejo ("Poesía popular ecuatoriana" 12) transcribe la siguiente serie:

En la tierra de humedá

nace yerba de contino:

ahí nace el amor-fino

donde hay buena voluntad.

Hasta la Reina ha salido

de su palacio ar camino

\footnotetext{
11 En la costa ecuatoriana se dice comúnmente chapulete a la libélula. "Tradicionalmente el chapulete, libélula, cortapelo, secapoza, etcétera, ha inspirado a literatos y artistas de diversas disciplinas e incluso en el argot citadino identificado con el folclore lingüístico se suele apodar 'chapulete' a aquellos amigos y parientes dueños de una apariencia delgadísima y de caminar rápido e inquieto" ("Los chapuletes, veranillos y aguas de abril en el folclore", 30 de abril de 2012.)

Súper Amorfinos Montubios, colección de bolsillo.

Cuaderno de Inés Rivera, "natural de Canuto".

Cuaderno de Vicenta Bazurto, "vecina de La Chorrera", Canuto.
} 
tan sólo por aprendé

lo’ versos del amor-fino.

Hasta er señó don Justino

me ha mandado a llamá

pa' que me ponga a cantá

lo versos del amor-fino.

El paralelismo de la primera cuarteta ya se muestra preceptora de una categorización moral que se transmitiría al imaginario colectivo, y que la conciencia misma portaría para extenderse. Donde la tierra es fértil crece la hierba de forma incesante. Así, se cosecharía el amorfino en corazones fértiles de buena voluntad, que se referirá a algo propio de destacar en lo humano "amor, cariño, afición, benevolencia o afecto" como figura de voluntad, según la sexta acepción del Diccionario de la Real Academia Española (drae). Simplificando, hay un guiño a la nobleza, lo cual sucede en el amor cortés. No obstante, ya hemos mencionado que no mantendrá la concepción del amor cortés, por más que haya una patente relación. Con todo, algo bueno que una reina querría aprender. Tan bueno, que un hombre de letras se interese en registrar. En las dos siguientes cuartetas, la misma copla varía ligeramente, son dos formulaciones que aconsejan a querer siendo correspondido y desistan cuando no lo sean.

Amorfino no seas tonto

aprende a tener vergüenza

la que te quiso quererla

la que no, no le hagas fuerza. ${ }^{15}$

Amor-fino no seas tonto

aprende a tené vergüenza

quiere a la que te quiere

ya la que no, no le haga juerza. ${ }^{16}$

\section{Vivencia y manifestación en el velorio con verso}

La vitalidad del amorfino se halla en la reproducción de estos versos cantados y declamados en rondas entre hombres y mujeres. Si las formas se ciñen a los modelos de una métrica española, al estilo y sentido de una lírica popular de tipo tradicional, serán su nueva dimensión discursiva, su imaginario tropical y el uso improvisado en el contexto lo que envuelve el carácter propio del subgénero. Trasladado de un contexto aldeano al de las cabeceras cantonales, y protagonizado por dos amorfineros con gracia para el verso, el género se desarrollará bajo ese principio dramático. De este modo, se debe hablar de un fenómeno sociopoético, cuyas expresiones residuales han sido objeto de estudio del folclore.

Manuel de Jesús Álvarez. Varios autores.

En Cornejo, "Poesía popular ecuatoriana" 112. 
Sobre este campo, Carvalho Neto (52) se inclina por superar la clasificación temática para "realizar una formulación que todavía estaba por hacer dentro del folclore poético, la cual consiste en registrar, modalidades, géneros, especies". Es decir, de acuerdo con las formas y funciones se decide esta tipología-nominal. El amorfino, como contrapunto y hecho folclórico, en otros lugares llamado payada cuando es competencia, lo podríamos incluir dentro del grupo circunstancial de parte del cancionero. En todo caso, encajaría en los tres grupos de tipo adulto (libre, circunstancial o cíclico): 1) Libre en su solo texto cuando se trata de coplas sueltas y se conciben individualmente bajo cierta emoción, bajo un aislamiento, como habrán sido compuestas y transmitidas en un gran caudal; 2) Circunstancial, dependiente de reuniones sociales, competencias en mercados comarcales y actualmente presentándose durante eventos o festivales culturales; y 3) Cíclico, pues esas manifestaciones ocurren en fechas señaladas, para el amorfino se asocian necesariamente al chigualo o a las navidades montubias.

El momento de máxima declaración de la copla amorosa está seguido de los versos cantados al Niño Dios en el pesebre. Durante esos autos de pastores, llamados en Manabí chigualos, se adora al Niño Jesús, y en las "bajadas del Niño" se despide al "recién nacido" hasta las próximas navidades. Aquellos cantos de adoración permiten el intercambio de versos; una persona canta los dos primeros versos y el resto de los presentes los repite, termina la copla con una nueva repetición del tercer y cuarto verso para, a continuación, dar paso al estribillo, que será otra copla. Es costumbre que los presentes en los cantos al pesebre conozcan los "versos del Niño", de forma que, cuando han repetido el segundo, suelen acompañar a la cantora en su primera entonación de los versos siguientes.

El chigualo se asocia con la tradición de pastoradas más bucólicas de la pequeña aldea ibérico-peninsular, comprendidas como expresiones dramáticas. Especialmente, se advierte mucha semejanza con el teatro medieval de tipo religioso de Castilla, estudiado por Maximiano Trapero. Estas obras "suelen representarse la noche de la Navidad dentro de las iglesias de los pueblos y en torno a la «misa del gallo»" (Trapero, Pervivencia del antiguo teatro 7). Cabe señalar que, en la hibridación cultural de América Latina se ensamblan ambas tradiciones: la hispana y la americana nativa. En su obra, Religiosidad popular en verso, el mismo Maximiano alude a la desaparición de muchas de estas tradiciones, y otras en riesgo de desaparecer, de ahí el subtítulo Últimas manifestaciones o manifestaciones perdidas del canto a lo Divino en España e Hispanoamérica. A propósito de su perduración:

[...] estas prácticas religiosas a nivel local han dependido de la fe, de la devoción, del entusiasmo y de la persistencia de una familia particular. Así ha ocurrido en la conservación de determinadas representaciones teatrales (autos de Reyes, pastoradas, pastorelas, etc.) o de la celebración de velorios (Trapero, Religiosidad popular en verso 81).

El chigualo montubio para explicarse debe ir seguido de ese adjetivo para no confundirse con los chigualos de las comunidades negras del Pacífico colombo-ecuatoriano. Entre ambos existe una gran diferencia, la tradición montubia es transmitida por la sistemática evangelización y se ha mantenido por la transmisión oral, siendo su fase inaugural y religiosa herencia de aquellos velorios o Autos de Navidad de León y Castilla como prefieren designar Joaquín 
Díaz y José Luis Alonso Ponga. En el estudio de estos encuentros, se observan la religiosidad y el relato de la síntesis de la cristiandad que subyace de los evangelios. Los chigualos se enlazan a un ritual en el que existen dinámicas de interacción y canto, cuyo origen resulta para Justino Cornejo menos inextricable que en otras expresiones culturales. Este fenómeno bien se define por su "Simiente española en surco americano" (Chigualito Chigualó 41), y reúne lengua y tradición hispana durante las fechas navideñas. No sucede así con el chigualo esmeraldeño ${ }^{17}$, cuya hibridación y sincretismo conserva un alto grado de los ingredientes de ancestros africanos.

Donde más arraigado está este fenómeno es en Manabí, por ello, no es raro que el ritual sea integrado en la llamada "Navidad de los Montubios" (Puga Palomeque). Se pueden encontrar hasta varios rituales de estos durante el mismo fin de semana, en diferentes barrios o comunidades. Muchos chigualos se celebran en la madrugada del 2 de febrero, coincidiendo con las Candelarias; cuando se despide al "Niño Jesús" hasta las próximas navidades. Hay chigualos de tipo velorio, íntimos y más familiares de entorno a una veintena de personas donde las cantoras (pues en su mayoría son féminas) hacen con la entonación momentos de gran trascendencia. Otro tipo muy común de chigualos es el velorio más público, agudamente llamado bailorio, abiertos como para recibir cien, doscientas o más personas.

Se trata de un encuentro religioso y también profano. A menudo son las catequistas de las aldeas quienes saben versos y toman la iniciativa, tanto para los cantos al Niño, como para, hoy, los prácticamente desaparecidos juegos con versos de amor. Era hora y lugar del fervor religioso y, casi al tiempo, deleite amoroso. Mediante rondas o canciones se conducía el juego y el baile con el que se recreaban los jóvenes. Varios de ellos, también citados por informantes son: "el baile del naranjito", "el baile del sombrerito", "el baile del mes de enero", "zapateando la calabaza", "le zumba el mango", "el goyo sabido" y otros muchos: "la canoita", "zapateando la calabaza", "la carbonerita", "la pastora", "doncella del prado", "el caminante", "las golondrinas", "los caracoles", "las gitanas", "la flor de la maravilla" y "el gavilán sabanero" (Ordóñez Iturralde, Amorfino; Zambrano, Folkore literario). Tres cosas en una misma: juego, baile y canción de chigualo, entre cantos al pesebre, mediada la petición de permiso al Dios nacido. Entonces se jugaba a la rueda, se cantaban versos de celos, amor, ofensas...; se intercambiaban amorfinos, galanteos, contrapuntos, o versos chocantes y burlescos que ofenden o avergüenzan, todas las coplas de amor y desamor, y que comúnmente se engloban dentro del amorfino.

En suma y a modo de consideración final, el amorfino es una composición poética sencilla cantada y reproducida popularmente por las gentes de litoral ecuatoriano. Su germen se encuentra en el folclor criollo hispanoamericano y sus formas se integran entre las líricas de tipo tradicional. Se enmarca como una manifestación cíclica en los velorios de Navidad, donde sus cantos fueron insumo para juegos de rueda tras la paraliturgia de villancicos al Niño

El chigualo esmeraldeño canta a los niños muertos de la comunidad. Son angelitos y se les vela de esta manera. En este caso, las fechas están condicionadas al fallecimiento de un pequeño y no a la clausura del periodo de fiestas en navidades. El chigualo se asocia con la ceremonia fúnebre de una menor de las comunidades negras del pacífico colombo-ecuatoriano. Parece muy probable que las comunidades montubias también, en intercambio con las negras de Esmeraldas, tomaran el nombre para su ceremonia más parecida a la peninsular. 
Jesús. El uso improvisado en el contexto revela algunas particularidades en su dimensión discursiva y en su imaginario. El carácter propio del fenómeno popular residió en la verdad que contenía la declamación y su finalidad se centraba en que esos versos podrían ser efectivos para despertar el amor. Por otro lado, en la segunda mitad del siglo xx, perdió vigencia ese uso popular y actualmente su expresión se reduce a la dramatización del folclore en el que dos (o más) amorfineros en escena, hombre y mujer, intercambian versos en un duelo verbal con finalidad de entretener y hacer reír a un público.

\section{Referencias}

Albaladejo, Tomás. Retórica. Madrid, Editorial Síntesis, 1991.

Alonso, Dámaso. “Introducción”. Cancionero y romancero español. Madrid, Salvat, 1969, pp. 9-19.

Alonso, Dámaso y José Manuel Blecua. Antología de la poesía española. (Lírica de tipo tradicional). 2 ed. Madrid, Gredos, 1978.

Canino Salgado, Marcelino. La copla y el romance populares en la tradición oral de Puerto Rico. San Juan, Instituto de Cultura Puertorriqueña, 1968.

Carvalho Neto, Paulo de. Folclore poético. Quito, Editorial Universitaria, 1966.

Cornejo, Justino. "Poesía popular ecuatoriana". Anales de la Universidad de Guayaquil. Archivo Histórico del Guayas. Vol. 2. Guayaquil, Departamento de Publicaciones de la Universidad de Guayaquil, 1951, pp. 193-218. Impreso.

Cornejo, Justino. Chigualito Chigualó: biografía completa del villancico ecuatoriano. Quito, Casa de la Cultura Ecuatoriana "Benjamín Carrión", 2005.

Deyermond, Alan David. Historia de la literatura española 1. La Edad Media. Traducido por Luis Alonso López. Barcelona, Ariel, 1973.

Díaz Viana, Luis. "La invención del concepto de 'Cultura Tradicional' en los estudios sobre poesía hispánica: las relaciones entre lo oral y lo escrito”. Entre la palabra y el texto: problemas en la interpretación de fuentes orales y escritas Editado por Luis Díaz Viana y Matilde Fernández Montes. Madrid, CSIC-Sendoa Editorial, 1997, pp. 1332 .

Díaz, Joaquín y José Luis Alonso Ponga. Autos de Navidad de León y Castilla. León, Santiago García Editor, 1983. 
Feijó, Samuel (dir.) Signos en la expresión de los pueblos. (Enero-abril). Santa Clara, Consejo Nacional de Cultura, 1975.

Fernández, Teodosio; Millares, Selena y Eduardo Becerra. Historia de la literatura hispanoamericana. Madrid, Universitas, 1995.

Frago Gracia, Juan Antonio. Historia del español de América. Textos y contextos. Madrid, Gredos, 1999.

Frago Gracia, Juan Antonio y Marian Franco Figueroa. El español de América. Cádiz, Servicio de Publicaciones de la Universidad de Cádiz, 2003.

García Berrio, Antonio y Javier Huerta Calvo, Javier. Los géneros literarios: sistema e historia. Madrid, Cátedra, 1995.

Gómez López, Nieves y José Manuel Pedrosa Bartolomé. Las voces sin fronteras: didáctica de la literatura oral y la literatura comparada. Vol. 25. Almería, Universidad Almería, 2016.

Kofman, Andrey. "La copla española en América Latina”. La Colmena: Revista de la Universidad Autónoma del Estado de México núm. 79 (julio-septiembre 2013): 65-78. Web. 20 Nov. 2021. https://www.redalyc.org/pdf/4463/446344315009.pdf

Lapesa Melgar, Rafael. Introducción a los estudios literarios.. Madrid, Cátedra, 1995.

Marimón Llorca, Carmen. "El español en América: de la conquista a la Época. Colonial". Biblioteca Virtual Miguel de Cervantes. Web. 20 Nov. 2021. http://www.cervantesvirtual.com/obra-visor/el-espaol-en-amrica-de-la-conquista-a-la-poca-colonial-0/ html/00f4b922-82b2-11df-acc7-002185ce6064_2.html

Menéndez Pidal, Ramón. Poesía árabe y poesía europea, con otros estudios de literatura medieval. Madrid, Espasa Calpe, 1963.

----. Poesía juglaresca y juglares. Aspectos de la historia literaria y cultural de España Sexta edición. Madrid, Austral, 1969.

Moliner, María. Diccionario de uso del español. Madrid, Gredos, 2004.

Monroy Zuluaga, Leonardo. "La imagen de la mujer en el mundo burgués latinoamericano: una lectura de Blanca Sol de Mercedes Cabello de Carbonera". La Palabra, núm. 37 (abril-junio de 2020): 75-86. https://doi.org/10.19053/01218530.n37.2020.9914

Navarro Tomás, Tomás. Métrica española reseña histórica y descriptiva. 6 ed. Barcelona, Labor, 1983. 
Ong, Walter J. Oralidad y escritura. Tecnologías de la palabra. México, Fondo de Cultura Económica, 1987.

Ordóñez Iturralde, Wilman. Amorfino. Canto mayor del montubio. Ecuador, Shamán Editores, 2004.

Pastor de Arozena, B. y Edward Roberts. Diccionario etimológico indoeuropeo de la lengua española. Madrid, Alianza Editorial, 1996.

Pérez Martínez, Javier. De la trova al amorfino y del juglar al montubio: coplas de amor como tradición oral del litoral ecuatoriano. Reflexiones desde la comunicación y la cultura: medios, identidad y formación. Coordinado por Daniel Barredo y Patricia Enríquez. Manta, Mar Abierto, 2016.

Pérez Martínez, Javier. "Una aproximación geopoética a la copla de amor: el río y la loma como mitos espaciales montubios". Castilla. Estudios de Literatura, núm. 11 (2020): 96-120. https://doi.org/10.24197/cel.11.2020.96-120

Puga Palomeque, Consuelo. El chigualo manabita: la fiesta navideña montubia. Quito, Fondo Editorial Ministerio de Cultura y Patrimonio, 2013.

Rivas, Robespierre. Amorfinos costeños. Guayaquil, ESPOL y Fundación Pedro Vicente Maldonado, 1990.

Sánchez Romeralo, Antonio. El villancico. Estudios sobre la lírica popular en los siglos XV y XVI. Madrid, Gredos, 1969.

Sánchez-Albornoz, Nicolás. La población de América Latina desde los tiempos precolombinos al año 2000. Madrid, Alianza Universidad, 1973.

Trapero, Maximiano. Pervivencia del antiguo teatro medieval castellano: la pastorada leonesa. Madrid, Fundación Juan March, 1981.

Trapero, Maximiano. Religiosidad popular en verso. Últimas manifestaciones o manifestaciones perdidas en España e Hispanoamérica. México, Frente de Afirmación Hispanista, 2011.

Zambrano, Domingo Nevaldo. Folkore literario: cultura popular, tradiciones orales. Manabí, Casa de la Cultura Ecuatoriana Núcleo Manabí, 2004.

\section{Relación de cuadernos de verseras}

Inés Rivera, Canuto, Chone, Manabí.

Elicio Alcívar, Canuto, Chone, Manabí. 
Cuaderno de Vicenta Bazurto, vecina de La Chorrera, Canuto, Chone, Manabí.

Súper Amorfinos Montubios, Colección de bolsillo. 